\title{
Visualizing detailed postdoctoral employment trends using a new career outcome taxonomy
}

\author{
Hong Xu, Richard S T Gilliam, Shyamal D Peddada, Gregory M Buchold \& Tammy R L Collins

\begin{abstract}
A standard taxonomy and visualization methods can provide postdoctoral scholars with tools to critically evaluate
\end{abstract} \\ their career prospects.
}

Dostdoctoral scholars are highly skilled scientists that, classically, have been trained to enter into academic tenure-track positions. However, the number of these tenure-track positions is remaining largely flat while the number of postdoctoral fellows is increasing, meaning that the majority of scientists will obtain other types of careers. To make informed decisions about these careers, scholars need institution-level knowledge about their options. Institutions have been implored to collect and report this information for decades, but the lack of a standard career outcome taxonomy and visualization method has severely impeded progress. Here, we address these impediments by developing a threetiered, hierarchical taxonomy and visualization methodology-creating standard definitions for: (i) job sectors (6); (ii) job types (7); and (iii) job specifics (20) - that will empower meaningful cross-institutional career outcome comparisons on a global scale. Applying our methods to intramural NIEHS alumni (50/50 US versus international), we report the first account of

Hong Xu, Richard S.T. Gilliam and Tammy R.L. Collins are in the Office of Fellows' Career Development, National Institute of Environmental Health Sciences, National Institutes of Health, Research Triangle Park, North Carolina, USA; Shyamal D. Peddada is in the Department of Biostatistics, Graduate School of Public Health, University of Pittsburgh, Pittsburgh, Pennsylvania, USA; and Gregory M. Buchold is in the Sheikh Khalifa Zayed Al Nahyan Institute for Personalized Cancer Therapy, The University of Texas MD Anderson Cancer Center, Houston, Texas, USA. e-mail: tammy.collins@nih.gov

Received 10 June 2017; accepted 21 September 2017; published online 15 January 2018; corrected after print 13 March 2018; doi:10.1038/nbt.4059 detailed career outcomes for all postdoctoral scholars present at NIH/NIEHS within the past 15 years, which revealed striking differences among subpopulations. US scholars enter into the for-profit sector in professional job-types conducting applied research at a much higher rate than international scholars. International scholars enter the academic sector in tenuretrack job-types conducting basic research at twice the rate of US scholars-but they pre-

dominantly enter into these positions outside of the US. Conversely, US scholars constitute the majority of those entering into tenuretrack positions within the US. The percentage of individuals obtaining tenure-track positions also varied widely by discipline, with those in biostatistics/computational biology leading the pack. We envisage that the standard taxonomy and visualization methods described here can be broadly applied to ascertain the finely tuned

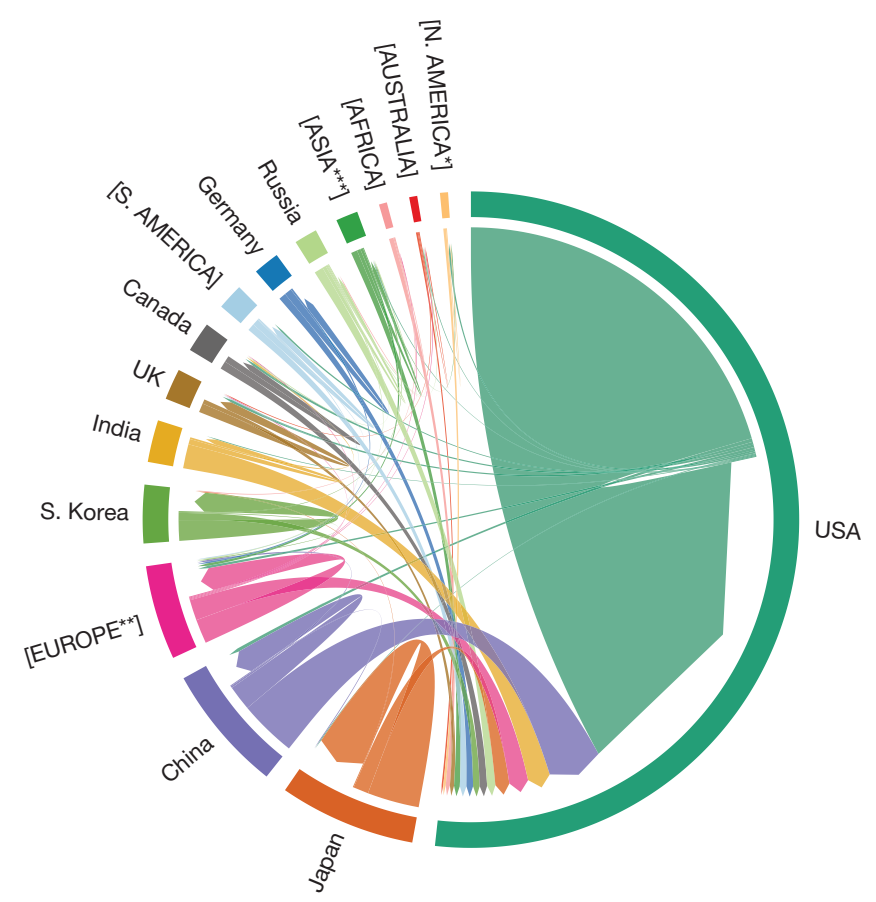

Figure 1 Visualizing alumni migration by pairing country/continent of origin with country/continent of job location. This circular plot displays the countries of origin alongside the countries of job location (arrows point to job locations). Nearly two-thirds of all alumni remain in the US after training, with fellows from Japan, South Korea, the UK and Germany returning to their home countries at greater proportions that the other countries shown. *North American countries excluding US and Canada;

**European countries excluding UK, Germany; ${ }^{* *}$ Asian countries excluding China, Japan, India and South Korea. Individual countries with enough alumni to visualize are shown in titlecase. Alumni from remaining countries are grouped and depicted by continent in all caps within enclosed brackets. 

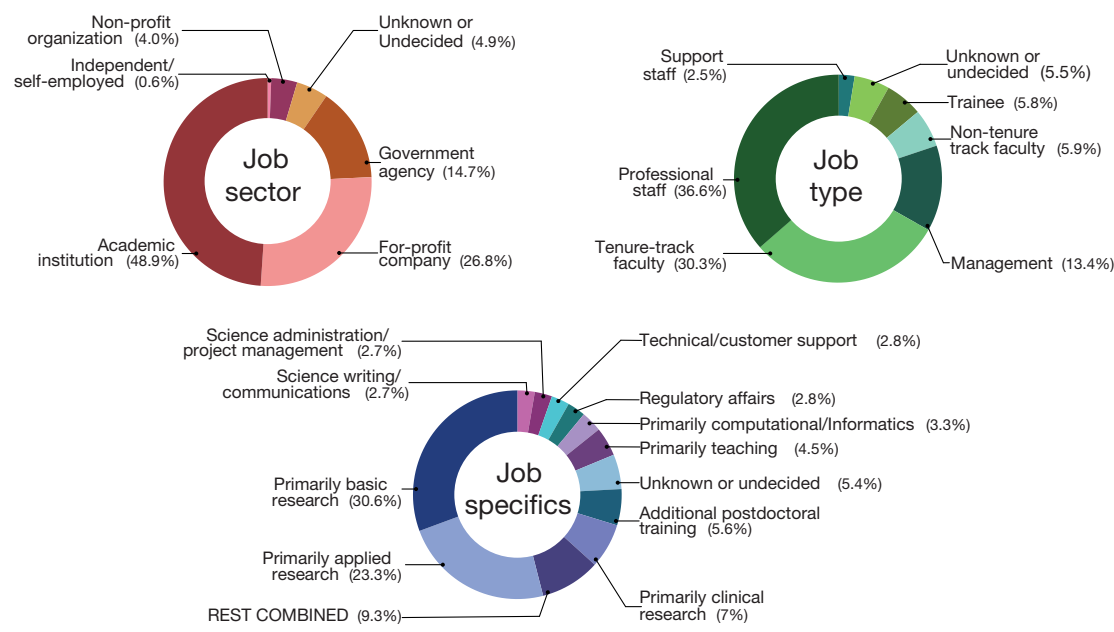

Figure 2 Summary of career outcomes within each tier of the taxonomy. Job sector: nearly half of all alumni enter the academic sector, while the remainder largely enter the for-profit or government sector. Approximately $5 \%$ are unknown or undecided. Job type: $30 \%$ enter into tenure-track positions, while more than one-third enter into professional staff positions, and the rest enter into non-tenure-track, support or trainee-type positions. Job specifics: nearly $70 \%$ of all alumni enter into research-based positions, whether basic, applied, clinical, computation/informatics or whether continuing research in another postdoc position. The remainder are mostly involved in science-related non-research positions. Each job specifics category in Supplementary Table 3 that was populated by less than 2.5\% of alumni (denoted by * within the table) was grouped into a category termed 'REST COMBINED' for ease of illustration.

career outcomes of postdoctoral scholars on a global scale.

\section{INTRODUCTION}

Postdoctoral scholars form the backbone of the global biomedical research enterprise. Historically, these traineeships have focused on preparing scientists for tenure-track research positions in academia. Analyses have shown that these tenure-track positions (whose numbers are remaining flat) are now imbalanced when compared to the quantity of $\mathrm{PhD}$-holders (whose numbers are increasing) (1,2 $^{1,}$ That raises the question: where are $\mathrm{PhD}$-holders working in this shifting career landscape? Many organizations have been asking this question for decades, imploring institutions to systematically track the career outcomes of $\mathrm{PhD}$-holders and release their findings to the public ${ }^{3,4}$. Despite these calls for institutional tracking, little institution-level data exist on the career outcomes of $\mathrm{PhD}$-holders, and the information that does exist is almost completely lacking in detailed specifics. This deficiency has led organizations such as the Council of Graduate Schools to implore institutions to dissect these finer details in order to provide more meaningful information to scientists evaluating their career prospects $^{5}$. Recent broad-scale efforts by the NIH Biomedical Workforce (BWF) Working Group (https://acd.od.nih.gov/documents/reports/ Biomedical_research_wgreport.pdf) among others ${ }^{5-7}$ are galvanizing individuals to collect and disseminate data at the institution-level ${ }^{8}$. Answering these calls, University of California, San Francisco researchers released a seminal study on the postdoctoral career outcomes at their institution ${ }^{9}$, contending that tracking career outcomes at the program level is more meaningful than national surveys, which collate information from individuals in a variety of fields and programs. This study came with limitations, however, given that the researchers only examined those within T32 program laboratories (NIH Institutional Training Grant Program for which career outcome data is more readily obtained from grant reports); and given that this study did not identify finely tuned information regarding job specifics. The difficulty in ascertaining this finely tuned information is partially owed to the lack of a standard taxonomy for classifying detailed career outcomes of $\mathrm{PhD}$-holders.

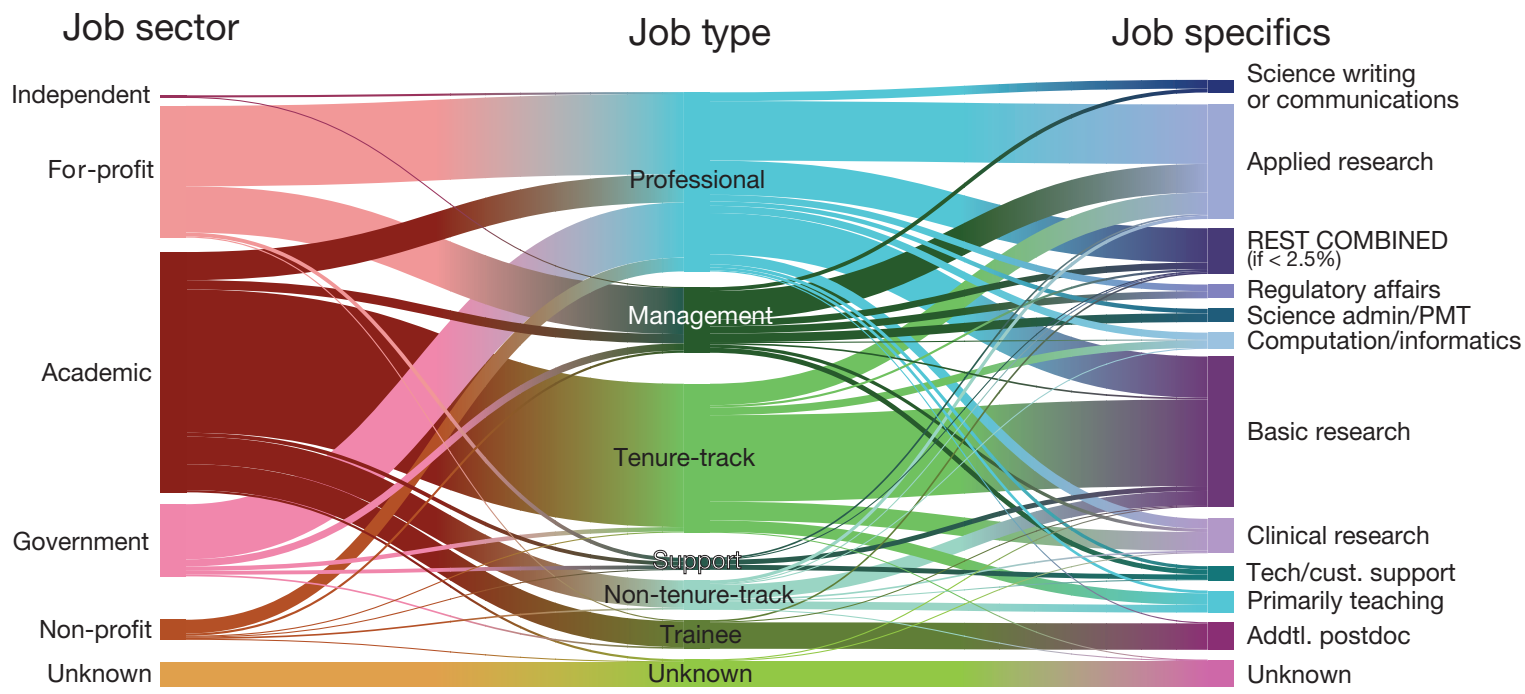

Figure 3 Relationship between job sectors, job types and job specifics. The width of the lines is proportional to the relative quantity of scholars within each group. Left and middle: division of job sectors by job type. Focusing on the academic sector as an example, it can be seen that while nearly half of all scholars enter into the academic sector, only $29 \%$ enter into academic tenure-track positions, as illustrated by the red to light-green transition. The remainder of those in the academic sector are divided between professional, management, support, non-tenure-track or trainee job types. Middle and right: division of job types by job specifics. Focusing on tenure-track positions as an example, it can be seen that the majority are conducting basic research in tenure-track positions ( $17 \%$ overall), which is illustrated by the green to dark-purple transition. Most of the remaining individuals in tenure-track positions are either teaching, or conducting applied or clinical research. 


\section{CAREERS AND RECRUITMENT}
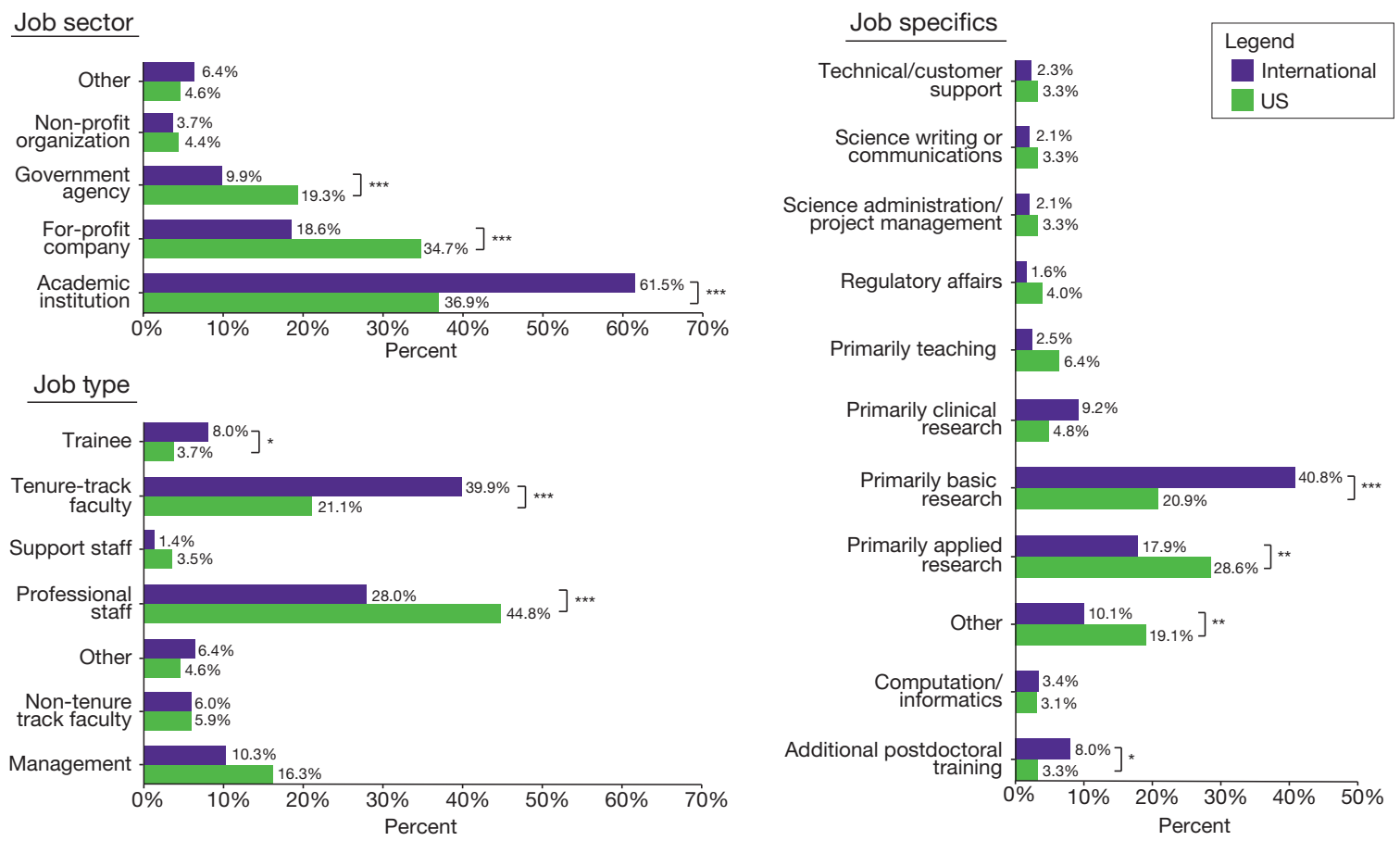

Figure 4 Career outcome variations among US and international scholars. Job sector: significantly more international scholars (purple) than US scholars (green) enter into the academic sector, while more US scholars enter into the for-profit and government sectors. Job type: nearly twice as many international scholars enter into tenure-track faculty positions and trainee positions compared with US scholars. Job specifics: significantly more international scholars ( $2 x)$ are conducting primarily basic research, while more US scholars are conducting applied research compared with international fellows. ${ }^{* *} P<0.001,{ }^{* *} P<0.01$, ${ }^{*} P<0.05$. Within this figure, 'Other' refers to a pooling of the remaining defined groups, which we combined due to small $N$-values within individual groups.

To address this problem, we developed a systematic, hierarchical method of classifying career outcomes into three tiers; our system was used by the overall NIH Intramural Research Program in 2014 as the standard for reporting internal preliminary career outcomes across NIH. The classification method we developed follows a logical progression from broad to increasingly more specific, and answers three general questions: (i) Where are individuals going? (ii) What position type/ level do they hold? (iii) What are they specifically doing in these positions? In answering these questions, we (i) developed a new, threetiered career outcome taxonomy based on job sector, job type and job specifics ${ }^{10}$; (ii) created standardized career outcome definitions; and (iii) developed tools that empower visualizing meaningful career outcome trends and impacts (Supplementary Methods, Supplementary Tables 1-4). We envision that these tools will facilitate global, cross-institutional career outcome comparisons, thus allowing prospective $\mathrm{PhD}$-holders to critically evaluate their options.

\section{RESULTS}

To demonstrate these tools in action, we identified US National Institutes of Health (NIH) National Institute of Environmental Health Sciences (NIEHS) postdoctoral alumni based on institutionally collected administrative data. The alumni included in this study are intramu- ral, meaning that they trained on-site at NIEHS, which is one of the $27 \mathrm{NIH}$ government institutes and centers where a wide range of basic and applied biomedical research is conducted in a model akin to academia. To find these alumni, we mined a multitude of websites and social media platforms allowing us to ascertain the detailed career outcomes of nearly all NIEHS postdoctoral alumni $(N=891)$ from 2000-2014 (Supplementary Methods). In reporting their outcomes, we demonstrate how our career outcome taxonomy, coupled with creative visualization, enables a wealth of information to be uncovered that was previously obscured.

\section{Demographics and job location}

At NIEHS, there are almost an equal number of international and US scholars (49\% international vs. $51 \%$ US). Binning them into three successive five-year periods revealed a small shift toward fewer international fellows over time (52\% international in 2000-2004, 50\% international in 2005-2009 and 45\% international in 2010-2014) (Supplementary Fig. 1). We observed that after fellows leave NIEHS, there are differences in where they obtain jobs, depending on whether they are international or US scholars. 91\% of US scholars remain in the US (415/455), while only $45 \%$ of international fellows (198/436) do. Creatively visualizing these data (Fig. 1) illustrates that about two-thirds of alumni from China and India remained in the
US (purple and yellow arrows pointing to the US, respectively), while only about one-fifth of alumni from Japan and South Korea remained, with most returning home (orange arch/arrow pointing back to Japan; green arch/arrow pointing back to South Korea). Interestingly, this migration pattern shares commonalities with trends uncovered by Franzoni et al. ${ }^{11}$, who conducted a comprehensive analysis of the mobility patterns of foreign-born scientists for 16 countries. Investigation of US state locations revealed that one-third of all alumni remained in North Carolina (294/891; Supplementary Fig. 2), the location of NIEHS. This trend is not surprising given that other studies show that individuals tend to settle near the areas where they receive training ${ }^{8}$. The next highest concentration of fellows included those in the Maryland/DC metro area, with the rest distributed across the US in a manner approximately proportional to state populations.

\section{Career outcome taxonomy}

To more carefully dissect the outcomes of these global scholars, we created a new, hierarchical career-outcome taxonomy, classifying fellows into three tiers based on their (i) job sector, (ii) job type and (iii) job specifics ${ }^{10}$, for which we developed standard definitions (Supplementary Tables 1-3) and demonstrated how to apply them (Supplementary Table 4). Using this taxonomy, we found that 
nearly half were employed within the academic sector, $27 \%$ were employed by for-profit companies, $15 \%$ were employed within the government sector and $4 \%$ were employed within the non-profit sector. Less than $5 \%$ were unknown or undecided (Fig. 2).

Looking at job types, we found that most held professional staff positions (37\%), while $30 \%$ were in tenure-track faculty positions-a figure higher than expected when compared to the 2012 NIH BWF report. Approximately 13\% were in management positions, while a nearequal number held non-tenure-track faculty and trainee-type positions, each at $6 \%$. Almost $5 \%$ were unknown or undecided, and an even smaller percentage $(2.5 \%)$ were in support staff job types (Fig. 2).

Answering (inter)national calls to provide more finely tuned details about career outcomes, we defined and examined 20 job 'specifics'. These specifics encompass different types of research (whether basic, applied, clinical), as well as a multitude of other nonresearch positions, including regulatory affairs and science writing or communication (Supplementary Table 3), for which standard definitions and categories are almost completely lacking. Upon examining the 'job specifics', we found that the majority $(70 \%)$ were conducting some type of research, whether primarily basic $(31 \%)$, applied $(23 \%)$, clinical (7\%), computation/informatics $(3 \%)$ or in the form of additional postdoctoral training $(6 \%)$. The remainder were largely engaged in science-related non-research, whether in the form of teaching (4\%), or in other areas such as regulatory affairs, science writing/communication and consulting, at percentages ranging from $<1 \%$ to $3 \%$ (Fig. 2).

Visualizing the relationship between each of these three main tiers-job sector, job type and job specifics (Fig. 3) -resulted in a graphic containing a wealth of information regarding career outcomes. We created this image-a Sankey diagram - by plotting the percentages within each tier (from Fig. 2) and connecting them to each other based on the relative proportions linking one category to another. The width of the lines depicts the quantity of scholars within each group. Focusing on the academic sector as an example, we found that while half of our alumni entered into academia-not all do so as tenure-track faculty. Only 29\% entered into academic tenure-track faculty job types, as seen from the brick-red to light-green transition. The remainder of those within the academic sector were divided between professional (6\%), management $(2 \%)$, support $(1 \%)$, non-tenure-track $(6 \%)$ or trainee $(5 \%)$ job types (Fig. 3). We next examined the relationship between job
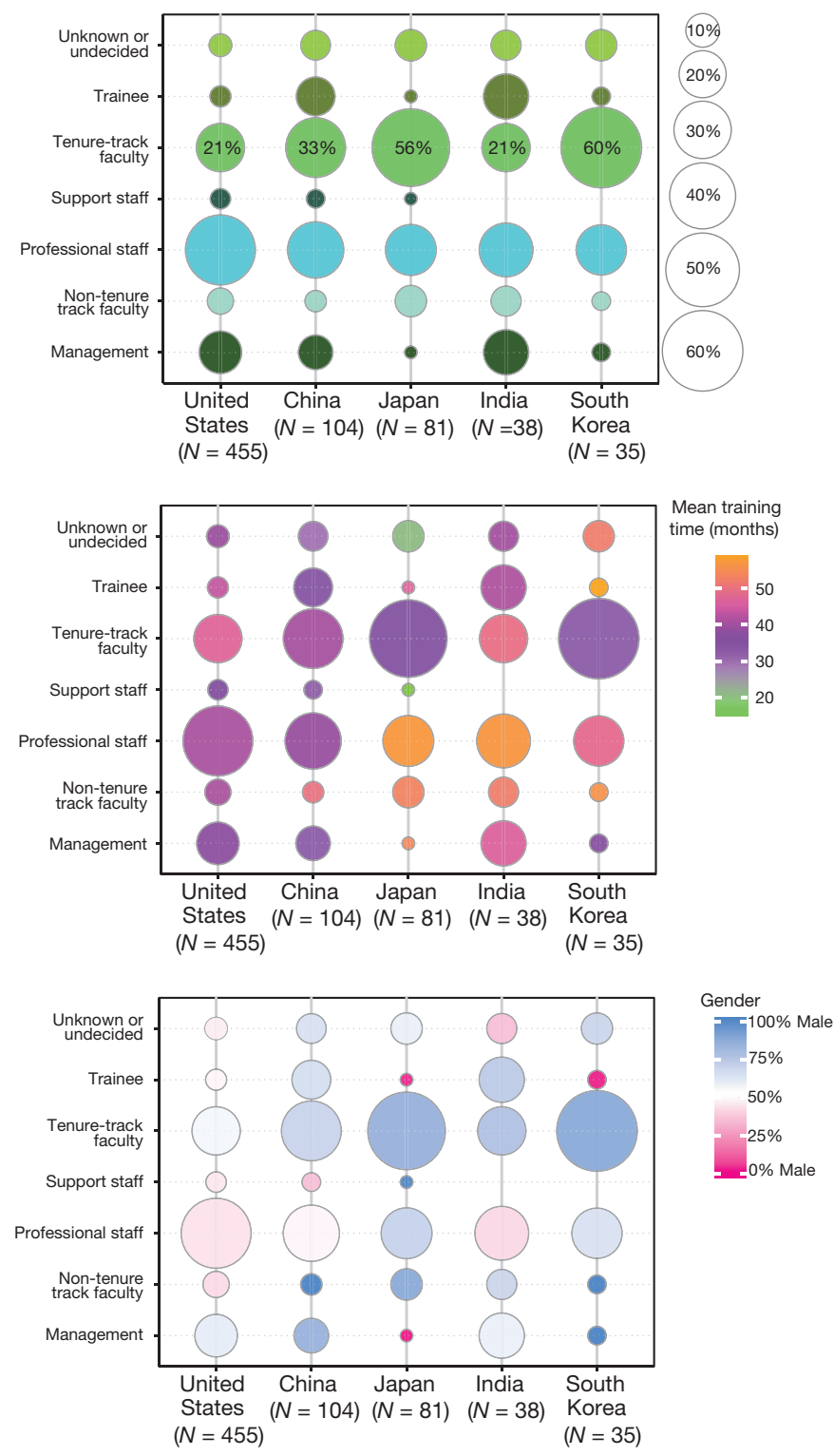

Figure 5 Variations among the 'Top 5' countries. Upper panel: job types vary between countries. A higher percentage of alumni from South Korea and Japan enter into tenure-track positions versus the remainder of the 'top five' countries based on number of alumni. Middle panel: training times vary between both job types and countries. Individuals from Japan and India entering into professional staff positions train the longest while those entering support staff roles have some of the shortest training times. Lower panel: gender composition varies between both job types and countries. The US has the most gender balance for those in tenure-track positions, while for Japan and South Korea, these positions are weighted toward males. Professional staff positions are more likely to be weighted toward females regardless of country origin. All panels: The legend depicting the size of the circles (10-60\%) applies to all panels. Percentages are based on the alumni outcomes within each individual country. For example, all circles on the solid gray line connecting the job types within the US sums to $100 \%$ of US alumni. All circles on the solid gray line connecting job types within China sums to $100 \%$ of Chinese alumni, etc.

types and job specifics by focusing on tenuretrack faculty job types as an example. Those in tenure-track faculty positions were largely conducting basic research (17\%, light-green to purple transition, Fig. 3 and Supplementary Fig. 3). Most of the remaining individuals in tenure-track positions were either teaching, conducting applied or clinical research, or engaged in computation/informatics research.

\section{Career outcome variations}

After determining overall career outcomes, we investigated variations within subpopulations, and found statistically significant differences between international and US scholars. These differences were apparent in all three tiers-job sectors, job types and job specifics (Fig. 4). Our results show that significantly more US scholars were employed within for-profit companies 
in professional positions conducting applied research, while international scholars obtained academic tenure-track faculty positions conducting basic research at nearly twice the rate of US scholars. Simply viewing the data in this manner does not tell the whole story, however. To truly understand these trends, we paired this information with job locations (Supplementary Fig. 4). In doing so, we found that while twothirds of all tenure-track faculty positions were held by international fellows (left panel; center circle, light magenta), a large proportion entered into these positions outside of the US ( $45 \%$ of all tenure-track positions held by international fellows abroad, outer circle, dark purple). Of the US fellows, most hold tenure-track positions within the US (left panel; outer circle, dark green), with only $3 \%$ of tenure-track positions being held by US fellows abroad (left panel; outer circle, light green). We also discovered that of all tenure-track jobs held within the US, US scholars obtained these positions by a $13 \%$ margin (33\% versus $20 \%$ ) over international scholars.

Given the stark career outcome differences between international versus US scholars, we investigated how this trend held up at the country level. Thus, we examined job types among the 'top five' countries from which most NIEHS trainees originate-the US, South Korea, Japan, India and China. The highest percentage of alumni entering tenure-track positions came from South Korea (60\%) and Japan (56\%) (Fig. 5). The next highest percentage of alumni holding tenure-track faculty positions originated from China (33\%). All three of these groups had more scholars with MD or $\mathrm{MD} / \mathrm{PhD}$ degrees compared with the US scholars (Supplementary Fig. 5), and anecdotal evidence suggests that many fellows from Japan and South Korea were on a defined path to enter a tenure-track position in their home country before conducting postdoctoral training at NIEHS. These fellows mostly returned to their home country where they likely entered into tenure-track positions awaiting them. It will be interesting to further dissect the career outcome differences between US and international alumni in future work, especially in light of studies suggesting that migration has a positive effect on scientific performance; this effect is predicted to result from the knowledge recombination gained from migration ${ }^{12}$.

In addition to variations between international and US fellows, we also examined career outcome differences based on an individual's field of study. We were able to ascertain $75 \%$ of the fields of study in which alumni obtained their advanced degrees. The top two most common fields of study were 'biochemistry/ biophysics/molecular biology' $(N=147)$ and 'pharmacology/toxicology' $(N=126)$, with these individuals obtaining tenure-track positions at rates of $24 \%$ and $22 \%$, respectively. The two fields with the highest percentage of alumni entering into tenure-track faculty positions were 'biostatistics/computational biology' at 58\% ( $N$ $=12)$ and epidemiology at $48 \%(N=29)$ (Fig. 6). To put these results in context, we examined both retrospective and prospective labor analyses. A retrospective labor gap analysis revealed an all-encompassing oversupply of graduate-level degree holders versus available jobs $^{13}$. However, this labor oversupply was less pronounced for statisticians and epidemiologists compared with general biological scientists, which may play a role in the increased proportion entering tenure-track positions. A prospective analysis by the US Department of Labor predicts that mathematicians and statisticians will experience much faster than average job growth ( $29 \%$ and $33 \%$, respectively) between 2016-2026, with epidemiologists experiencing average growth (9\%) over this same time frame (https://www.bls.gov/ooh/fastest-growing.htm).

\section{DISCUSSION}

Whether the biomedical research enterprise trajectory is sustainable has been a topic of recent national debate ${ }^{14}$. A key issue in this debate is the question of how to properly train the increasing number of PhD-holders for their shifting career landscape. Largely missing from this debate are data on the career outcomes of $\mathrm{PhD}$-holders, a taxonomy of career outcomes, detailed information about specific career paths and a creative method that enables visualizing career trends to gain comprehensive insight into them. To remedy these gaps, we undertook this study in order (i) to determine the career paths of postdoctoral fellows who trained at a government institution within the past 15 years, and identify whether various subpopulations had statistically significant differences in their career outcomes; (ii) to extend our analysis beyond general career outcomes, and paint a clear picture of the 'specific' job activities of our postdoctoral alumni; (iii) to create a career outcome taxonomy by developing standard definitions and classifying individuals in a three-tiered manner assigning a job sector, a job type and job specifics; (iv) to develop creative methods of visualizing career outcome data in order to make the information more accessible; (v) to contribute to the international conversation on postdoctoral career outcomes by providing a standard basis for future cross-institutional comparisons that could be

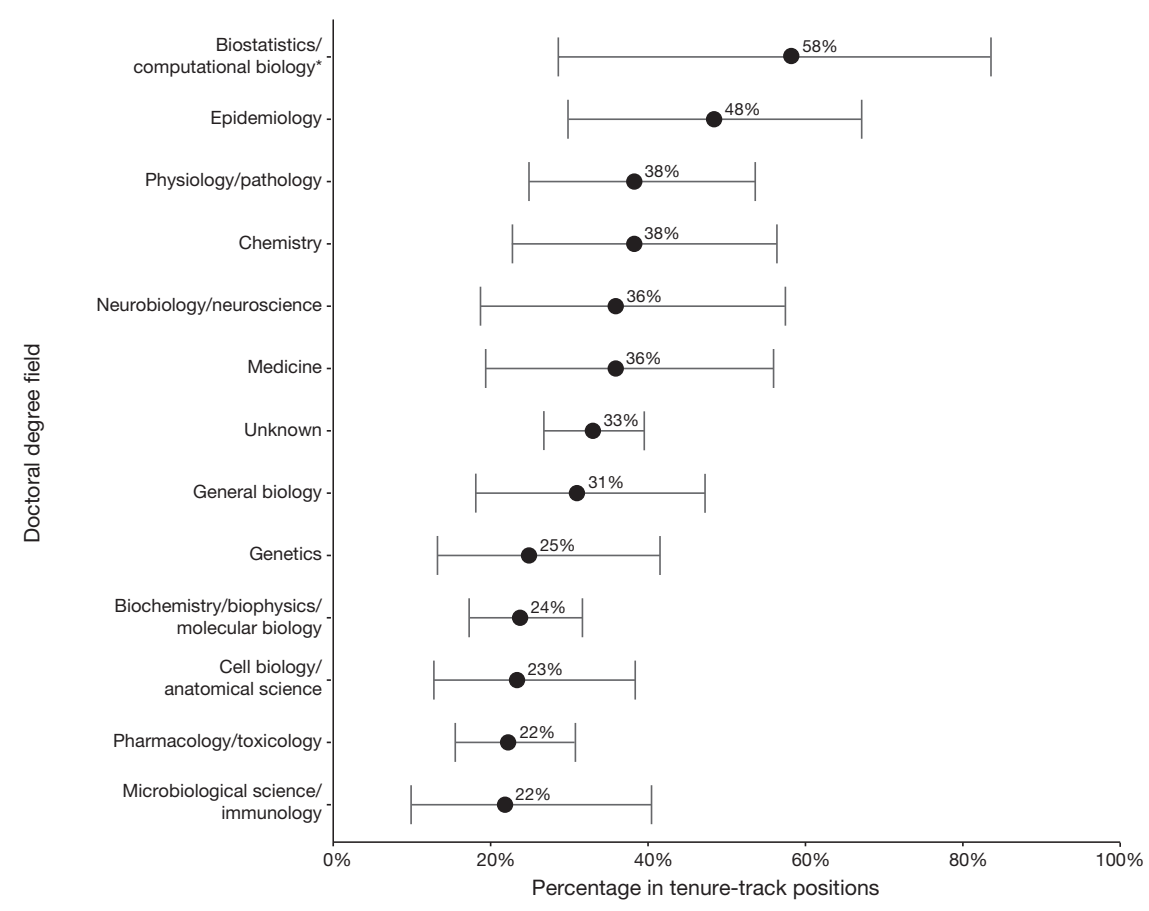

Figure 6 Percentage of alumni that enter into tenure-track positions based on their doctoral degree field. Alumni doctoral degree fields were standardized according to the main program groups defined within NCES' Biological and Biomedical Sciences instructional programs. The relative percentage of alumni within each degree field entering into tenure-track positions is shown. The $95 \%$ confidence intervals for the binomial proportion are shown here. ${ }^{*}$, the main NCES program group is 'Biomathematics, Bioinformatics, and Computational Biology;' 'Biostatistics' was substituted for 'Biomathematics' and 'Bioinformatics' within the title because nearly all alumni in this category possessed a degree in statistics or biostatistics. 
broadly applied to ascertain finely tuned career outcomes of postdoctoral scholars on a global scale; and (vi) to provide prospective and current $\mathrm{PhD}$-holders with tools to identify career paths and trends based on rigorous data analysis at the institution and subpopulation level.

A noteworthy feature of our study is that it represents a nearly complete (95\%) sample of the entire postdoctoral population at NIEHS within the past 15 years, enabling us to avoid selection or sample bias and draw impactful conclusions about the career outcomes at a governmental institution. Our three-tiered taxonomy allowed us to easily re-sort data in order to compare our results with other collective studies, such as the 2012 NIH BWF report. Re-sorting data in the manner described within Supplementary Figure 6 revealed statistically significant differences between our cohort and that within the BWF report. Nearly twice as many NIEHS scholars were conducting government research (11.3\% versus $5.5 \%, P<0.001$ ), and a significantly higher proportion held tenure-track faculty positions (30\% NIEHS versus $23 \%$ BWF, $P<0.001)$. Furthermore, preliminary findings from an analysis of self-respondents to the NIH Office of Intramural Training and Education (OITE) alumni database (which includes a sampling of fellows from across all NIH institutes and centers) yielded near-identical results compared to ours when examining the government sector and tenure-track job types (https:// oitecareersblog.wordpress.com/2017/03/13/). Collectively, these results suggest that conducting a postdoctoral fellowship within the government is associated with a higher probability of entering into a government sector career, and a government postdoc does not hinder one's chances of obtaining a tenure-track faculty position within academia. The only remaining area in which we saw a statistically significant difference was in 'non-science-related-research', with $13.3 \%$ from the NIH BWF versus $1 \%$ at NIEHS (Supplementary Fig. 6). We consider this comparison unreliable, however, given that 'non-science-related-research' was ill-defined, which further illustrates a fundamental need for the methodology described herein.

\section{Influence of location}

A large proportion of scholars remained in North Carolina. In fact, of all those who remained in the US, nearly half remained in North Carolina. This strongly suggests that the career outcomes of scholars are heavily influenced by the types of jobs within close proximity. One of the most striking examples of this logic can be explained when examining those who enter into science policy careers. At NIEHS, the only NIH institute fully outside of the Maryland/DC metropolitan area, very few alumni $(0.2 \%)$ entered into a career within science or public policy. In contrast, findings from the broader NIH postdoctoral community, which is mainly located within the DC metropolitan area, suggest that a significant proportion of fellows enter into science policy-in fact, 40 individuals, or $6 \%$ ( $20 \%$ of science-related non-research) of self-respondents to the NIH OITE database reported entering into a career within science policy. While we again note that these findings are preliminary, it stands to reason that their seemingly higher entrance into these careers is heavily influenced by their close proximity to DC, where science policy careers are concentrated (https://www.aaas.org/page/ frequently-asked-questions). This supposition is reinforced by other studies such as that conducted at Wayne State University in Michigan, in which nearly $50 \%$ of their doctoral alumni remained in Michigan ${ }^{8}$. We thus feel that institutions should take these trends into consideration when designing their training programs. While the location trends suggest that many are using the connections and resources within their surrounding community, we point out that centralized, online resources exist for the purpose of educating scholars about a range of career path options that may extend beyond localities. An excellent example of such a resource was created by the NIH OITE, which maintains a wealth of online material and videocasts regarding "How-To" obtain positions within a variety of different career paths (https://www.training.nih.gov/oite_videocasts).

\section{Conclusions and looking ahead}

The new career outcome taxonomy shown here allowed us to conduct a highly detailed analysis of postdoctoral career outcomes. Using these methods, we identified specific outcomes for an unbiased cohort of all postdoctoral scholars (95\%) present at NIEHS within the past 15 years, and we coupled this taxonomy with creative visuals to unmask the impact of our findings. We hope that the taxonomy, definitions and visualization methods presented will eliminate a key hurdle in career outcome reporting and analysis-inspiring others to use our methodology so that more finely tuned, meaningful, institution-level information will be available for cross-comparisons within the global scientific research community. Having this institution-level information will allow prospective and current doctoral candidates to evaluate their career prospects based on real data, rather than anecdotes. Likewise, this information will allow institutions to critically evaluate the effectiveness of their programs, so that data-driven decisions can be made to provide programming that supports student transitions into the modern career environment.
Note: Any Supplementary Information and Source Data files are available in the online version of the paper.

\section{ACKNOWLEDGMENTS}

We thank W. Schrader for helpful suggestions regarding the taxonomy design. We thank J. Collins for helpful suggestions regarding data analysis, and helpful comments on the manuscript. We thank P. Wade, L. Conlan, K. McCann, H. Vellers, M. Longley, C. Flowers and V. McGovern for helpful discussions and comments on the manuscript. This research was supported by the Intramural Research Program of the NIH, National Institute of Environmental Health Sciences (CAN 8380839 to T.R.L.C.).

\section{AUTHOR CONTRIBUTIONS}

T.R.L.C. designed research; T.R.L.C., H.X., R.S.T.G. and G.M.B. collected data; T.R.L.C., H.X., R.S.T.G. and S.D.P. analyzed data; and T.R.L.C. and H.X. wrote the paper.

\section{COMPETING FINANCIAL INTERESTS}

The authors declare no competing financial interests.

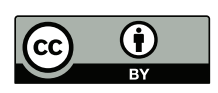

This article is licensed under a Creative Commons Attribution 4.0 International License, which permits use, sharing, adaptation, distribution and reproduction in any medium or format, as long as you give appropriate credit to the original author(s) and the source, provide a link to the Creative Commons license, and indicate if changes were made. The images or other third party material in this article are included in the article's Creative Commons license, unless indicated otherwise in a credit line to the material. If material is not included in the article's Creative Commons license and your intended use is not permitted by statutory regulation or exceeds the permitted use, you will need to obtain permission directly from the copyright holder. To view a copy of this license, visit http://creativecommons.org/ licenses/by/4.0/

1. Cyranoski, D., Gilbert, N., Ledford, H., Nayar, A. \& Yahia, M. Nature 472, 276-279 (2011).

2. National Science Foundation, National Center for Science and Engineering Statistics. Doctorate Recipients from US Universities: 2014. NSF Special Report 16-300 (National Science Foundation, Arlington, 2015).

3. Institute of Medicine, National Academy of Sciences, and National Academy of Engineering. Enhancing the Postdoctoral Experience for Scientists and Engineers: a Guide for Postdoctoral Scholars, Advisers, Institutions, Funding Organizations, and Disciplinary Societies (The National Academies Press, Washington, D.C., 2000). doi:10.17226/9831

4. National Academy of Sciences, National Academy of Engineering, and Institute of Medicine. The Postdoctoral Experience Revisited (The National Academies Press, Washington, 2014). doi:10.17226/18982

5. Allum, J., Kent, J. \& McCarthy, M. Understanding PhD Career Pathways for Program Improvement: a CGS Report (Council of Graduate Schools, Washington, 2014).

6. National Science Foundation, National Center for Science and Engineering Statistics. Doctorate Recipients from US Universities: 2015. NSF Special Report 17-306 (National Science Foundation, Arlington, 2017).

7. Sinche, M.V. Next Gen PhD: a Guide to Career Paths in Science (Harvard University Press, Cambridge, 2016).

8. Feig, A.L. et al. Change: Mag. Higher Learn. 48, 42-49 (2016).

9. Silva, E.A., Des Jarlais, C., Lindstaedt, B., Rotman, E. \& Watkins, E.S. PLoS Biol. 14, e1002458 (2016)

10. Collins, T.R.L. et al. FASEB J. 30, 883.2 (2016).

11. Franzoni, C., Scellato, G. \& Stephan, P. Nat. Biotechnol. 30, 1250-1253 (2012).

12. Franzoni, C., Scellato, G. \& Stephan, P. Econ. Lett. 122 89-93 (2014).

13. Mason, J.L. et al. FASEB J. 30, 2673-2683 (2016).

14. Alberts, B., Kirschner, M.W., Tilghman, S. \& Varmus, H. Proc. Natl. Acad. Sci. USA 111, 5773-5777 (2014). 


\section{Erratum: Visualizing detailed postdoctoral employment trends using a new career outcome taxonomy}

Hong Xu, Richard S T Gilliam, Shyamal D Peddada, Gregory M Buchold \& Tammy R L Collins

Nat. Biotechnol. 36, 197-202 (2018); published online 15 January 2018; corrected after print 13 March 2018

In the version of this article initially published, the Creative Commons license was omitted. The error has been corrected in the HTML and PDF versions of the article. 